\title{
Sleep-related breathing disorders: definitions and measurements
}

\author{
W.T. McNicholas*, P. Levy**
}

Respiratory disorders during sleep have become recognized in recent decades as an important branch of respiratory medicine. These disorders include conditions that are present only during sleep, particularly sleep apnoea, and other respiratory disorders such as chronic obstructive pulmonary disease (COPD) that are evident during the awake state, but may be aggravated by sleep. Obstructive sleep apnoea syndrome is a common medical disorder, affecting $1-4 \%$ of the adult population in Europe according to different epidemiological surveys $[1,2]$. This prevalence implies that the condition is second only to asthma among chronic respiratory disorders. Remarkably, the syndrome was first described in the modern medical literature only $\sim 35$ yrs ago, although references in the classical literature clearly indicate that sleep apnoea syndrome has affected humanity from antiquity [3].

The definition of sleep apnoea syndrome has evolved over the past $25 \mathrm{yrs}$, initially being confined to the frequency of apnoeas per hour of sleep [4]. The clinical importance of hypopnoeas was later recognized [5], and, more recently, the importance of linking respiratory disturbances during sleep to symptoms, particularly daytime sleepiness, has been emphasized. The diagnostic evaluation of sleep apnoea has also evolved with time, initially being based exclusively on polysomnography in a dedicated sleep laboratory. However, as the high prevalence of the disorder has been recognized, it has become clear that such an exclusive diagnostic approach is not practical in all cases. This recognition has led to the evolution of limited sleep studies, and also the development of sleep study techniques outside the sleep laboratory, particularly in the home environment.

The evolution of the approach to the diagnosis of sleep apnoea syndrome has been somewhat haphazard. It is clear from the extensive published literature that there is no clear consensus regarding either the diagnostic classification of sleep apnoea syndrome and other sleep-related breathing disorders or the most appropriate measurement techniques to apply in the assessment of these disorders. This lack of consensus led to the establishment of a task force by the American Academy of Sleep Medicine in 1997, in conjunction with the European Respiratory Society (ERS), the American Thoracic Society and the Australasian Sleep Association. The present authors represented the ERS. This task force brought together 15 experts in respiratory

\footnotetext{
*Sleep Disorders Unit, St Vincent's University Hospital, Dublin, Ireland. **Sleep laboratory, EFCR, CHU Michallon, Grenoble, France.

Correspondence: W. McNicholas, Dept. of Respiratory Medicine, St Vincent's University Hospital, Elm Park, Dublin 4, Republic of Ireland. Fax: 35312697949.
}

sleep medicine from around the world for the specific purpose of developing recommendations for the definition of clinical syndromes related to sleep-related breathing disorders in adults, and also to provide recommendations concerning the most appropriate measurement techniques to be used in the evaluation of these disorders.

The work of the Task Force involved a number of meetings of the members, including working groups to evaluate particular aspects of the brief in detail. In addition, feedback was sought from members of the participating societies, usually by means of open discussion forums during annual meetings of the relevant societies. Finally, peer review of the draft report was obtained from a large number of outside experts. The final report was published in the journal Sleep in late 1999 [6], and has been described by many as a landmark in the evolution of the approach to the diagnosis and assessment of sleep-related breathing disorders. In addition to sleep apnoea syndrome, the report also addressed other sleep-related breathing disorders such as upper airway resistance syndrome, Cheyne-Stokes respiration, and sleep hypoventilation syndrome. Standard approaches to the evaluation of levels of evidence were utilized in the evaluation of the scientific literature relevant to each aspect of the brief. In some instances, the scientific literature available allowed clear evidence-based recommendations to be provided in the report. In other instances, the scientific literature was regarded as sufficiently weak that no clear evidence-based recommendations could be provided. In these circumstances, recommendations were made by a consensus drawn from the task force membership as a whole.

The Task Force considered the potential clinical significance of recurring episodes of increased upper airway resistance associated with arousal and sleep fragmentation, but not apnoea or hypopnoea, as originally described by Guilleminault et al. [7]. The Task Force agreed that these upper airway resistance episodes should be called respiratory effort-related arousals (RERA) and be considered part of obstructive sleep apnoea/hypopnoea syndrome (OSAHS). The definition of hypopnoea has been variable and unclear for many years. An important recommendation was that a hypoponea should be scored in the case of a reduction in flow of $>50 \%$ measured by a validated means, or a reduction of $30-50 \%$ associated with either an arousal or a desaturation of $>3 \%$.

The definition of OSAHS severity in the report categorizes the syndrome into mild, moderate and severe categories, with mild OSAHS including a combined apnoea, hypopnoea and RERA frequency of as low as 5 events $\cdot h^{-1}$, providing other symptoms such as daytime sleepiness are also present. This diagnostic threshold is lower than many 
experts would have previously regarded as appropriate, but is based on emerging evidence from carefully designed prospective studies such as the Wisconsin Sleep Cohort that have shown clear evidence of adverse health effects such as hypertension, sleepiness and motor vehicle accidents above this threshold $[8,9]$. It should be remembered, however, that these epidemiological studies were conducted using methods of measurement of flow that are less sensitive than the techniques presently available, such as use of nasal cannulae. Thus, this threshold may well need further adjustments in the future.

Many of the existing techniques available to measure respiration during sleep, such as respiratory inductance plethysmography and use of thermal flow sensors, are rated in the report on the basis of existing scientific evidence. In each case, evidence comparing the measurement technique to a reference standard was evaluated, and a level of recommendation provided based on this evidence. The report also identifies deficiencies in the available scientific evidence related to syndrome definition and measurement techniques, and provides recommendations for future research and development in this area. One of the most important and controversial recommendations of this report was that thermal sensors no longer be used for flow assessment.

A report of this nature clearly has limitations, particularly when it becomes apparent that the existing literature does not allow clear evidence-based recommendations to be made regarding many aspects of syndrome definition and measurement techniques. These limitations were highlighted in two editorials that accompanied the report in the same issue of Sleep $[10,11]$. However, the report provides the most comprehensive evaluation of the literature available to date in this area, and the recommendations made concerning syndrome definition allow some measure of uniformity to be introduced into clinical practice. Finally, the report provides a platform for future research, identifying areas of deficiency in the existing evidence base, and also encouraging the use of standard definitions and measurements that will facilitate comparison of studies. The conclusions and recommendations of this Task Force cannot be viewed as a final result, but rather as a staging point along the path of understanding sleep-related breathing disorders. It is hoped that future research triggered by this report will allow more evidence-based recommendations in the future, and further reports of this type will inevitably follow.

\section{References}

1. Gislason T, Almqvist M, Eriksson G, Taube A, Boman G. Prevalence of sleep apnoea syndrome among Swedish men - an epidemiological study. J Clin Epidemiol 1988; 41: 571-576.

2. Stradling J, Crosby J. Predictors and prevalence of obstructive sleep apnoea and snoring in 1001 middle age men. Thorax 1991; 46: 85-90.

3. Kiely JL, McNicholas WT. Overview and historical perspectives of sleep apnoea syndrome. Eur Respir Mon 1998; 3: 10, pp. 1-8.

4. Guilleminault C, Tilkian A, Dement WC. The sleep apnea syndromes. Ann Rev Med 1976; 27: 465-484.

5. Gould GA, Whyte KF, Rhind GB. The sleep hypopnea syndrome. Am Rev Respir Dis 1988; 137: 895-898.

6. The Report of an American Academy of Sleep Medicine Task Force. Sleep-related breathing disorders in adults: recommendations for syndrome definition and measurement techniques in clinical research. Sleep 1999; 22: 667689.

7. Guilleminault C, Stoohs R, Clerk A, Cetel M, Maistros P. A cause of excessive daytime sleepiness. The upper airway resistance syndrome. Chest 1993; 104: 781-787.

8. Young T, Peppard P, Palta M, et al. Population-based study of sleep-disordered breathing as a risk factor for hypertension. Arch Intern Med 1997; 157: 1746-1752.

9. Young T, Blustein J, Finn L, Palta M. Sleep-disordered breathing and motor vehicle accidents in a population-based sample of employed adults. Sleep 1997; 20: 608-613.

10. Quan SF, Gillin JC. New definitions of sleep disordered breathing - not yet a mandate for change in clinical practice. Sleep 1999; 22: 662.

11. Littner MR, Shepard JW. Recommendations for research into measurement and classification of sleep disordered breathing: gazing into the crystal ball. Sleep 1999; 22: 665666. 